\title{
A survey of people with ventriculoperitoneal shunts in the community Roger Bayston ${ }^{* 1}$ and Rosemary Batchelor ${ }^{2}$
}

\author{
Address: ${ }^{1}$ BRIG Divn of Orthopaedic and Accident Surgery, C Floor West Block, QMC, Nottingham, NG7 2UH, UK and ${ }^{2}$ Association for Spina \\ Bifida and Hydrocephalus, ASBAH House, 42 Park Road, Peterborough, PE1 2UQ, UK \\ Email: Roger Bayston* - roger.bayston@nottingham.ac.uk \\ * Corresponding author
}

from 52nd Annual Meeting of the Society for Research into Hydrocephalus and Spina Bifida

Providence, RI, USA. I I-I4 June 2008

Published: 3 February 2009

Cerebrospinal Fluid Research 2009, 6(Suppl I):S46 doi:10.II86/I743-8454-6-SI-S46

This abstract is available from: http://www.cerebrospinalfluidresearch.com/content/6/SI/S46

(c) 2009 Bayston and Batchelor; licensee BioMed Central Ltd.

\section{Background}

The most common route for shunting in most countries is now ventriculoperitoneal (VP). Reasons for switching from ventriculoatrial (VA) to VP shunting include the need for more revisions and the greater risk of infection in VA shunts. While in the nosocomial setting healthcare workers are very familiar with shunt problems, this might give a skewed impression of their actual prevalence, and the purposes of this survey were firstly to establish the situation regarding VP shunted people in the community not currently receiving medical attention, and secondly to compare them to those in our previous 2006 survey of people with VA shunts.

\section{Materials and methods}

A randomly selected group of 405 people known to have VP shunts from the ASBAH database were contacted with a simple questionnaire containing five questions and space for comments: Do you have a VP shunt? If so, for how long have you had it? Have you ever had a VP shunt? If so, how long did it last? Have you ever had problems with your VP shunt such as blockage or infection? (if yes, say what they were). The responses were then collated.

\section{Results}

Of the 405 people selected from the database, 128 responded. Eight were excluded from analysis ( 5 for insufficient data returned, 3 incorrectly entered - no VP shunt). 117 still had a VP shunt, and 3 now had a $3^{\text {rd }}$ ventriculostomy. Of those who still had a VP shunt, it had been in place for a mean of $13.4 \mathrm{yrs}$ ( 1 week to $40 \mathrm{yrs}$ ) compared to 30.8 yrs (0.3-44 yrs) for VA. 43 people (35.8\%) reported no shunt problems ( $38 \%$ for VA). The VP infection rate per patient was $20 \%(12.75 \%$ for VA); VP obstruction in $44 \%$ ( $48 \%$ for VA); VP catheter disconnections $13.7 \%$ (10\% for VA). The rate of slit ventricles was similar in each group (VP 4\%, VA 2\%). When the number of shunt revisions was compared per patient shunt year, there were 0.133 for $\mathrm{VP}$, and 0.077 for VA.

\section{Conclusion}

Based on self - reporting, both VP and VA shunts appear to perform better and for longer than expected based on surveys and impressions from hospital patients. The rate of some problems for VA and VP is similar, but there were fewer infections and fewer revisions in VA shunts, contrary to popular expectation. These data are useful to inform patients and carers, and surgeons who need to resite a shunt in case of repeated complications. 